\title{
BRAGANTIA
}

Revista Cientifica do Instituto Agronômico, Campinas

\section{ESTRESSE DE ÁGUA NO CRESCIMENTO, PRODUTIVIDADE E ACUMULO DE PROLINA EM FEIJÃO $\left({ }^{1}\right)$}

Haiko E. Sawazaki $\left({ }^{2}\right)$, J. P. Fexjão Teixeira, Seção de Fitoquímica, e Luiz D'ARTAGNan de Almbida $\left({ }^{3}\right)$, Seção de Leguminosas, Instituto Agronômico

\section{RESUMO}

O objetivo deste trabalho foi verificar o comportamento de dez cultivares de feijâo (Phaseolus vulgaris L.) em condiçóes de falta de água em relação ao crescimento das plantas, produçăo e acúmulo de prolina, num ensaio conduzido em casa de vegetaçäo, com os tratamentos irrigado e com periodos sem irrigação. Avaliaram-se a área foliar, peso seco, altura das plantas e teor de prolina livre nas folhas durante o desenvolvimento e peso dos grãos no final do ciclo. Os resultados mostraram que os cultivares Moruna e Aroana apresentaram as maiores taxas de desenvolvimento e menor acúmulo de prolina quando se compararam as plantas nāo irrigadas e as irrigadas, ao contrário dos cultivares Jalo, Roseli e Rosinha $G_{q}$. Em função do desenvolvimento e do acúmulo de prolina, suportaram melhor a seca os cultivares Moruna e o Aroana, sendo os mais suscetiveis 'Jalo' e 'Roseli'.

\section{INTRODUÇÃO}

A capacidade de acumular prolina, observada durante a falta de água, tem sido associada com a tolerância das plantas a essa condição desfavorável. Assim, JAGER \& MEYER (5) e MACHADO et alii (6), estudando plantas de feijão, evidenciaram a possível importância ecológica desse fato para a planta, por ser um mecanismo de adaptação para superar períodos curtos de seca. Sendo a prolina um aminoácido altamente hidrófilo, capaz de estabilizar colóides e processos metabólicos no tecido, armazenando carbono, nitrogênio e energia, os citados autores consideraram a possibilidade de plantas com maior habilidade em acumular prolina suportarem maiores déficits hídricos. $\mathrm{O}$ metabolismo da prolina não está, no entanto, totalmente desvendado.

A oxidação da prolina em folhas de cevada, segundo STEWART (9), pode ter uma função reguladora, atuando em acordo com o controle de

\footnotetext{
(1) Trabalho apresentado na XXXII Reuniāo Anual da Sociedade Brasileira para o Progresso da Ciência, 6 a 12 de julho de 1980, Rio de Janeiro (RJ). Recebido para publicaçāo a 5 de dezembro de. 1980.

(2) Com bolsa de aperfeiçoamento do CNPq.

(") Com bolsa de pesquisa do CNPa.
} 
Vol. 40, Art. n. ${ }^{\circ} 15$

síntese para manter a prolina livre a baixos níveis em tecidos túrgidos. Em tecido desidratado ocorre, portanto, a inibição da oxidação de prolina para que haja seu acúmulo.

BENGTSON et alii (1) sugerem que a prolina acumulada seja utilizada para a biossíntese de clorofila imediatamente após a reidratação, além de ser utilizada para outros caminhos metabólicos e síntese de proteína.

HANSON et alii $(2,3,4)$ revelaram que o acúmulo de prolina em plantas de cevada pode ser apenas um sintoma do efeito deletério provocado pela falta de água, não se podendo definir plantas com alto acúmulo de prolina, como tolerantes à seca. $\mathrm{O}$ menor acúmulo de prolina, resultante da capacidade de manutenção de alto nível de água durante o estresse, poderia ser considerado um fator de sobrevivência da folha. Esses autores supõem que as diferentes taxas de acúmulo de prolina podem ser atribuídas a diferenças na taxa de diminuição do potencial de água ( $\psi$ folha), pois, para um mesmo $\psi$, dois cultivares de cevada, um suscetível e outro resistente, continham teores similares de prolina livre. Conseqüentemente, diferenças na taxa de acúmulo de prolina entre esses genótipos devem ser devidas a diferenças genéticas na capacidade para manter o nível de água durante estresse severo, que é, ao menos em parte, dependente dos estômatos. Através de cruzamentos de linhagens de cevada suscetível e resistente, mostraram que a capacidade de acumular prolina é hereditária.

SAWAZAKI et alii (8) encontraram em vinte linhagens e cultivares de feijão diferentes taxas de acúmulo de prolina em função da disponibilidade de água no solo, tendo reunido o material estudado segundo a capacidade de acumular esse aminoácido.

\section{MATERIAL E METTODOS}

Em experimentos realizados em casa de vegetação foram utilizados dez cultivares de feijão (Phaseolus vulgaris L.): Rosinha $\mathrm{G}_{2}$, Bico de Ouro, Mulatinho Simétrico, Moruna, Rico 23, Aroana, Jalo, Roseli, Roxinho e Carioca.

Efetuou-se o plantio em vasos de $12 \mathrm{~kg}$, com composto terriço esterilizado com brometo de metila e adubação com fósforo e potássio, utilizando-se oito sementes por vaso e deixando-se três plantas após o desbaste.

Os vasos, num total de 240 , foram dispostos em seis blocos. Os vasos-testemunha e tratamento foram distribuídos de modo a constituir dois sub-blocos alternados em cada bloco. Os dez cultivares foram dispostos ao acaso em cada sub-bloco.

No $16 .^{\circ}$ dia após a germinação das sementes suspendeu-se a irrigação dos vasos-tratamentos por quatorze dias. Após esse período de estresse de agua, eles foram irrigados por duas semanas, suspendendo-se novamente a irrigação por uma semana durante a floração. A seguir, as plantas receberam irrigação até o final do ciclo.

Durante cinco semanas consecutivas, a partir do início do estresse e a cada sete dias, foram medidas a área foliar e o peso seco pela amostragem de duas plantas por tratamento, e o desenvolvimento pela amostragem de uma planta por tratamento e por bloco. O alongamento, estimado pela altura das plantas, foi verificado através de seis repetições; a área foliar 
foi medida com duas repetições através de medidor eletrônico de área $\mathrm{e}$ o peso seco após secagem das plantas em estufa com circulação forçada de ar a $60^{\circ} \mathrm{C}$ por 48 horas. $\mathrm{O}$ peso de grãos foi avaliado no final do ciclo.

Após cada período de falta de água foram amostradas plantas para a avaliação do acúmulo de prolina. Para tanto, retirou-se uma amostra composta de três discos de $1,6 \mathrm{~cm}$ de diâmetro de folhas primárias por planta, que foram imersos rapidamente em solução de metanol-clorofórmio-água (MCW), 12:5:1 (v/v/v) e mantidos então a $-5^{\circ} \mathrm{C}$ para máxima redução dos processos metabólicos. A média do peso seco de discos de folhas de plantas não irrigadas foi de $18,549 \mathrm{mg} \mathrm{e}$, das irrigadas, de $14,826 \mathrm{mg}$. A amostragem dos discos foliares foi efetuada aos nove e quatorze dias durante o estresse de água, com uma repetição por bloco. $\mathrm{O}$ teor de prolina foi determinado segundo metodologia descrita por RENA \& MASCIOTTI (7), que utiliza reação do aminoácido com solução ácida de ninhidrina e determinação fotométrica a $515 \mathrm{~nm}$.

\section{RESULTADOS E DISCUSSÃO}

$\mathrm{O}$ quadro 1 apresenta os dados referentes ao crescimento das plantas em função de tratamentos. Para os parâmetros avaliados, houve diferença significativa pelo teste de Tukey a $5 \%$ em função dos tratamentos para peso seco, área foliar, altura e produção por planta, sendo os maiores valores para o tratamento irrigado (plantas testemunhas).

Pelo quadro 2, verifica-se que os cultivares Roseli e Jalo apresenta- ram os maiores valores para peso seco, altura e produção, enquanto os menores foram encontrados nos cultivares Aroana, Moruna e Rico 23 para produção de grãos, peso seco, altura e área foliar.

Ocorreu interação entre cultivares e tratamentos, revelando comportamento diferente dos cultivares em função daqueles. Ao se estudar o efeito dos tratamentos em cada variedade separadamente, houve efeito significativo no peso seco, altura e produção de grãos de todos os cultivares, sendo que, para área foliar, apenas 'Rosinha $\mathrm{G}_{2}$ ', 'Jalo', 'Roseli' e 'Carioca' diferiram com o tratamento. A área foliar, que estatisticamente parece não ser um bom parâmetro para testar os cultivares quanto ao tratamento de escassez de água, fornecee, no entanto, boa indicação de estresse de água.

No quadro 3 são apresentadas a relação percentual entre plantas sob estresse e plantas testemunhas para cada cultivar e parâmetro. 'Moruna' e 'Aroana' foram os que apresentaram as maiores relações de crescimento quando se compararam as plantas não irrigadas com as irrigadas. 'Jalo', 'Roseli' e 'Rosinha $G_{2}$ ' foram os mais afetados pela falta de água e que percentualmente cresceram menos em relação às plantas irrigadas.

Como se pode verificar pelo quadro 4 , os cultivares mais afetados foram os que apresentaram maior acúmulo de prolina, sendo que 'Moruna' e 'Aroana', menos afetados pela falta de água, apresentaram os menores teores de prolina livre acumulada em suas folhas. Houve diferença em função do acúmulo de prolina para as testemunhas, tendo apresentado os maiores acúmulos 'Jalo' e 'Roseli' e, 


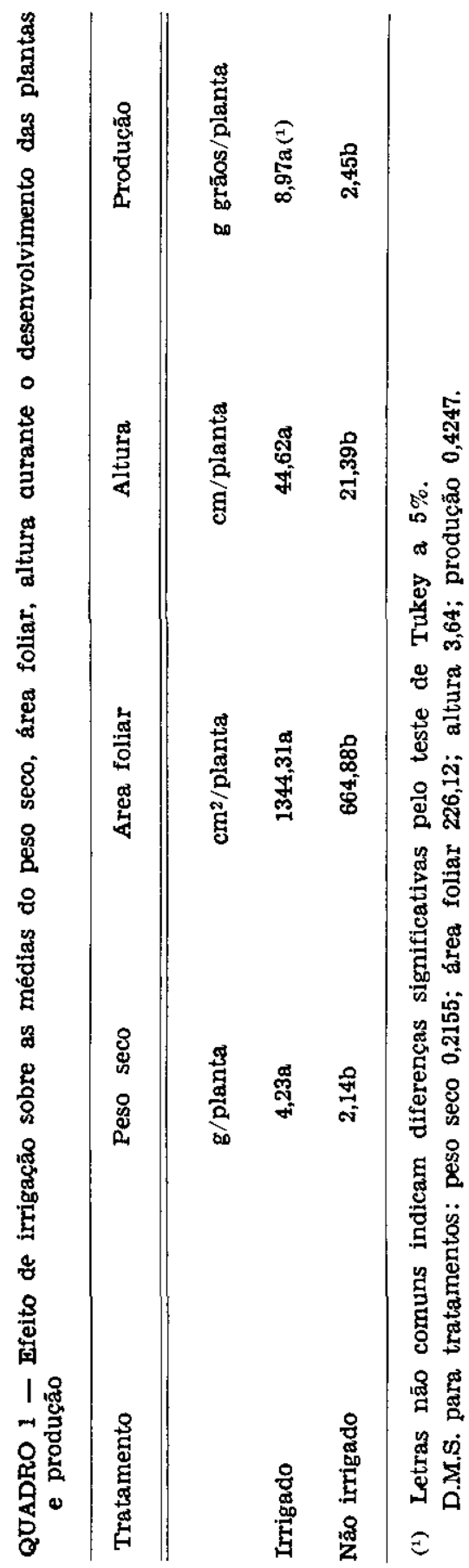


籴

है

㝝

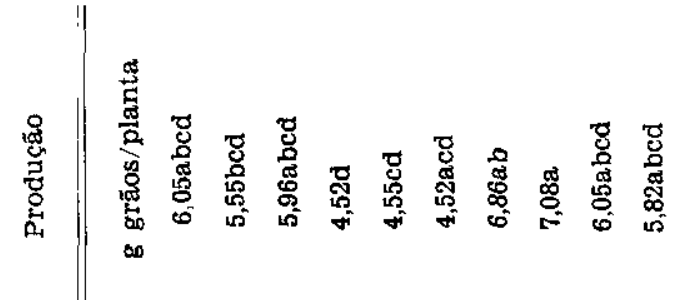

$\circ$

㹂

焉

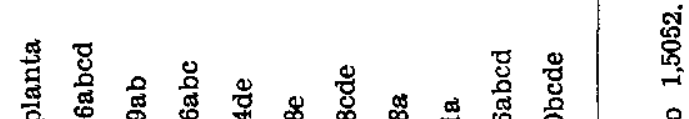

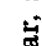

急 营 总

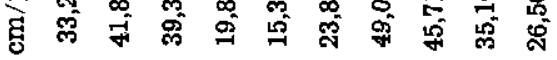

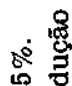

a 总

苗

害

8

号

\%

㺃

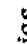

觉

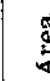

.

욤

马ี

窇

造

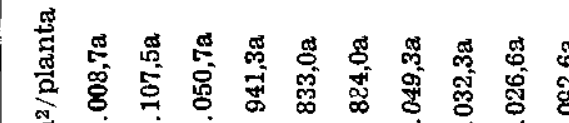

है

畓

若。

密弮 
要

:

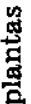

我

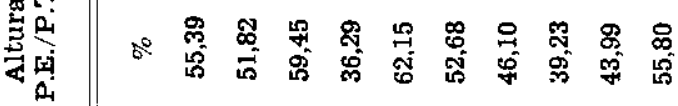

营

営

覃

운

起壱

退莺

总然

\&

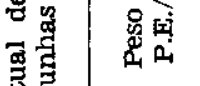

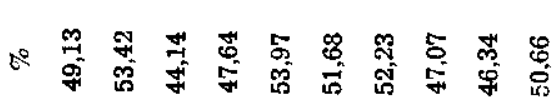

票皆

ن

2 势点

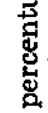

密要

1

की

贯

空点

号

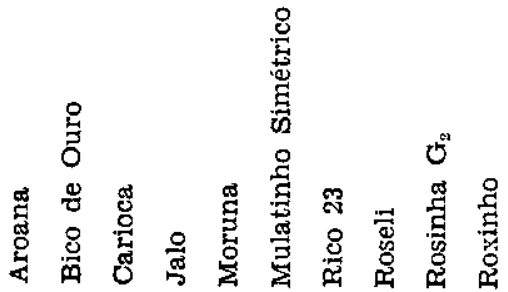


o menor, 'Moruna'. Com o tratamento de nove dias de ausência de irrigação, o que mais acumulou foi o 'Jalo' e o que menos acumulou foi o 'Moruna', e com quatorze dias de ausência de irrigação, os de maiores acúmulos foram 'Jalo' e 'Roseli' e, o de menor acúmulo, o 'Moruna'. Considerando-se, de acordo com HANSON et alii (3), que o acúmulo de prolina só se inicia após a planta atingir um limite correspondente ao ponto de turgescência zero, explicam-se as ligeiras diferenças nos teores de acúmulo com nove e quatorze dias de escassez pela variação de disponibilidade de âgua às plantas, que atingiram o potencial da água limite em épocas distintas.
O comportamento dos cultivares quanto ao acúmulo de prolina foi semelhante aos dados obtidos por SAWAZAKI et alii (8).

Verifica-se, pela figura 1 , que 'Jalo', sob estresse hídrico, tem acentuada redução do crescimento a partir da primeira semana de retirada da água, quando a taxa de prolina, já alta, aumenta de modo mais acelerado; isso significa que o início do acúmulo de prolina em 'Jalo' ocorreu antes do nono dia de estresse, enquanto no 'Moruna' foi posterior ao nono dia, indicando que, embora a taxa de crescimento do 'Moruna' diminua bastante após a primeira semana da retirada da água, esse cul-

QUADRO 4 - Acúmulo de prolina livre em folhas de vários cultivares de feijoeiro de plantas irrigadas ou năo-irrigadas

\begin{tabular}{|c|c|c|c|}
\hline \multirow{3}{*}{ Cultivar } & & \multicolumn{2}{|c|}{$\begin{array}{l}\text { Acúmulo de prolina em micromol/grama de } \\
\text { matéria seca de folha }\end{array}$} \\
\hline & & \multicolumn{2}{|c|}{ Sem irrigação } \\
\hline & & 9 dias & 14 dias \\
\hline Rosinha $\mathrm{G}_{2}$ & $1,47 \mathrm{ab}$ & $6,17 \mathrm{ab}$ & $16,88 \mathrm{ab}\left({ }^{1}\right)$ \\
\hline Bico de Ouro & $1,40 \mathrm{ab}$ & $5,32 \mathrm{abc}$ & $14,62 \mathrm{bc}$ \\
\hline Mulatinho Simétrico & $1,35 \mathrm{ab}$ & $4,73 \mathrm{bcc}$ & $11,67 \mathrm{~cd}$ \\
\hline Aroana & $1,27 \mathrm{ab}$ & $2,14 \mathrm{~cd}$ & 8,19 de \\
\hline Moruna & $1,09 \mathrm{~b}$ & $1,24 \mathrm{~d}$ & $6.85 \mathrm{e}$ \\
\hline Rico 23 & $1,25 \mathrm{ab}$ & $2,31 \mathrm{~cd}$ & $14,21 \mathrm{bc}$ \\
\hline Jalo & $1,49 \mathrm{a}$ & $8,94 a$ & $20.11 \mathrm{a}$ \\
\hline Roseli & $1,54 \mathrm{a}$ & $6.34 \mathrm{ab}$ & $20.46 \mathrm{a}$ \\
\hline Roxinho & $1,40 a b$ & $3.14 \mathrm{bcd}$ & 10,59 cde \\
\hline Carloca & $1,43 \mathrm{ab}$ & $5,09 \mathrm{bc}$ & $11,86 \mathrm{~cd}$ \\
\hline
\end{tabular}

(1) Letras não comuns indicam diferenças significativas pelo teste de Tukey a $5 \%$.

D.M.S. (Tukey $5 \%$ )

0,3928

3,6800

4,6500 
tivar entra em déficit hídrico mais tardiamente que o 'Jalo'. Convém lembrar que esse déficit tardio do 'Moruna' pode ter sido causado pelo menor porte da planta e menor necessidade de água durante todo o ciclo, pois, pela figura 2 , verifica-se que a área foliar do 'Moruna' não diminui tão sensivelmente quanto a do 'Jalo', quando ambos estão sob estresse, indicando que o 'Moruna' sofreu menos com a escassez de água.

O quadro 5 apresenta a comparação dos dez cultivares submetidos a tratamento com e sem irrigação após trinta dias da germinação.

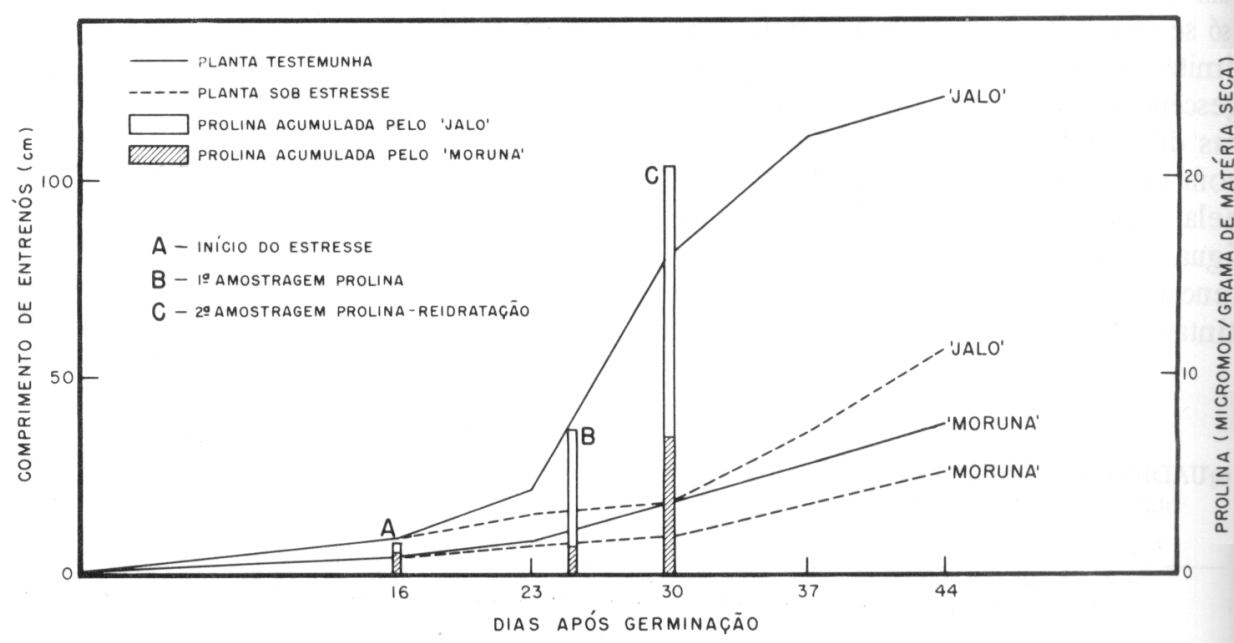

Figura 1. - Comprimento de entrenós e acúmulo de prolina após nove e quatorze dias de estresse de âgua nos cultivares de feijão Jalo e Moruna.

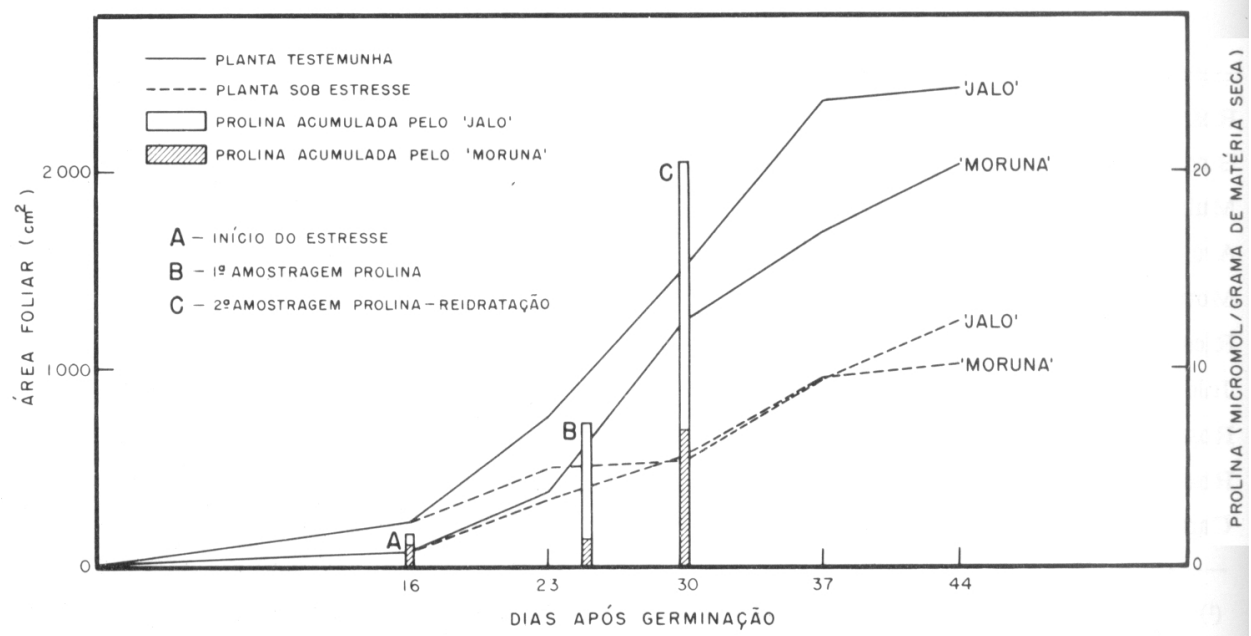

Figura 2. - Area foliar e acúmulo de prolina após nove e quatorze dias de escresse de água nos cultivates de feijăo Ja lo e Moruna 


\%

营

苔魚

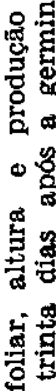

离它

过

讷

을

$\Phi$

잉

$\circ \%$

唯

总

1 .

is

옹

舟要

量

家

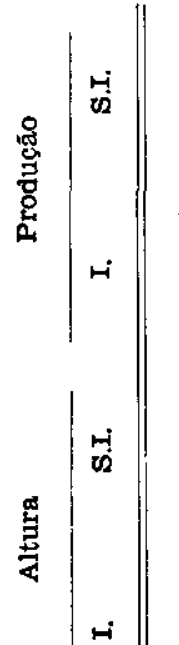

ఘึ

范

के

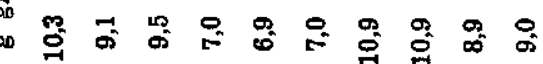

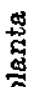

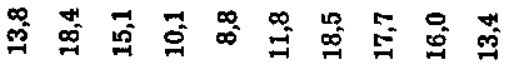

a

छ్

号 点

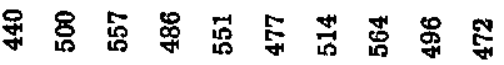

ปึี

芦

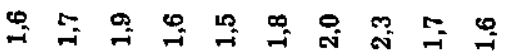
畨

$\Rightarrow$ \#

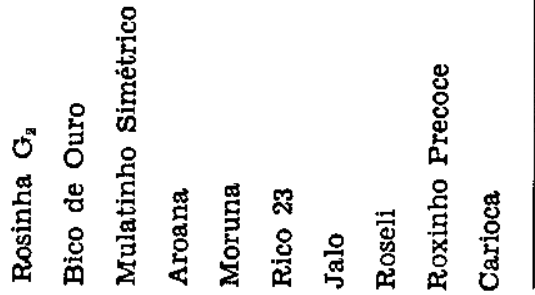




\section{CONCLUSÕES}

a) Os cultivares mais afetados pela escassez de água foram os que apresentaram maior acúmulo de prolina.

b) Os cultivares que acumula- ram mais prolina estiveram relacionados com o maior crescimento global.

c) Os que mais acumularam prolina foram 'Jalo' e 'Roseli' e os que menos acumularam foram 'Moruna' e 'Aroana'.

\section{SOIL WATER DEFICIT ON THE DEVELOPMENT, YIELD AND PROLINE CONTENT OF 10 DRY BEAN CULTIVARS}

\section{SUMMARY}

The objective of this paper was to verify the behavior of dry bean cultivars (Phaseolus vulgaris $L_{\text {.) }}$ related to the development, yield and free proline accumulation when subjected to waters stress.

Ten dry bean cultivars were grown in greenhouse with two treatments (a) irrigated, and (b) without irrigation for some periods.

Leaf area, dry weight, height, leaf proline content were determined several times during the growing season and grain yield at the end of plants cycle.

The results showed that the cultivars Moruna and Aroana showed the highest rate of development and the lowest accumulation of free proline when the two treatments were compared.

It can be concluded from the data that the cultivars Moruna and Aroana presented the highest drought resistance and the cultivars Jalo and Roseli the lowest.

\section{REFERENCIAS BIBLIOGRAFICAS}

1. BENGTSON, C.; KLOCKARE, B.; KLOCKARE, R.; LARSSON, S.; SUNDGVIST, C. The after-effect of water stress on chlorophyll formation during greening and the 'evels of absicisic acid and proline in dark grown in wheat seedlings. Physiologia Plantarum, 43:205-212, 1978.

2. HANSON, A. D.; NELSEN, C. E.; EVERSON, E. H. Evaluation of free proline accumulation as an index of drought resistance using two contrasting barley cultivars. Crop Science, $17(5): 720-726,1977$.

3. — - - PEDERSEN, A. R.; EVERSON, E. H. Capacity for proline accumulation during water stress in barley and its implications for breeding for drought resistance. Crop Science, 19:489-493, 1979.

4. - - TULLEY, E. R. Proline accumulation in water-stressed barley leaves in relation to translocation and the nitrogen. Plant Physiology, 63(3): 518-523, 1979.

5. JAGER, H. J. \& MEYER, H. R. Effect stress on growth and proline metabolism of Phaseolus vulgaris $\mathrm{L}$. Oecologia, $30: 83-96,1977$.

6. MACHADO, R. C. R.; RENA, A. B.; VIEIRA, C. The effect of osmotic dehydration on the accumulation of free proline in leaf discs of 20 bean cultivars (Phaseolus vulgaris L.). Revista Ceres, Viçosa, 23(128):302-309, 1976.

7. RENA, A. B. \& MASCIOTTI, G. Z. The effect of dehydration an nitrogen metabolism and growth of 4 bean cultivars (Phaseolus vulgaris L.). Revista Ceres, Viçosa, 23(128):288-301, 1976.

8. SAWAZAKI, H. E.; TEIXEIRA, J. P. F.; ALMEIDA, L. D'A. Variaçăo do teor de prolina em folhas de feijāo em função da disponibilidade de água no solo. Bragantia, Campinas, 40:47-56, 1981.

9. STEWART, C. R. The effect of wilting on proline metabolism in excised bean leaves in the dark. Plant Physiology, 51:508-511, 1972. 